\title{
A TEMPESTIVIDADE DOS LUCROS CONTÁBEIS OBSERVADA POR MEIO DO RETORNO ANORMAL ACUMULADO E DA VARIÂNCIA DO RETORNO ANORMAL
}

\section{THE TIMING OF ACCOUNTING PROFITS BY THE VIEW OF ACCUMULATED ABNORMAL RETURN AND THE VARIATION OF ABNORMAL RETURN}

Agradecimentos: À Fundação de Amparo à Pesquisa e Inovação do Espírito Santo (FAPES) pelo apoio financeiro ao autor Gilmar Gomes Gazzoni Junior.

\section{RESUMO}

Nesta pesquisa foi analisada a interação entre o lucro contábil e a tempestividade da divulgação e do pagamento dos lucros aos acionistas, utilizando o retorno anormal acumulado calculado através do Modelo de Mercado (Ball e Brown, 1968) e a variância do retorno anormal (Beaver, 1968). Entende-se como tempestividade da distribuição dos lucros, o momento em que ocorreu a divulgação ou o pagamento da remuneração aos acionistas: durante o exercício corrente ou após a divulgação do resultado do exercício. Com isso, procuram-se evidências de impacto da tempestividade da distribuição do resultado do exercício na informatividade do lucro contábil. Foi aplicada a metodologia de estudo de evento em uma amostra contendo 832 eventos de empresas listadas na B3, abrangendo a divulgação dos resultados ocorridos de 2011 a 2017. As evidências apontam que a tempestividade da divulgação da remuneração aos acionistas é mais relevante do que a do pagamento, estando condizente com a Hipótese dos Mercados Eficientes. As evidências encontradas indicam que a variância do retorno anormal possibilita identificar o impacto da nova informação ao preço das ações de forma mais clara do que pelo retorno anormal acumulado, calculado pelo Modelo de Mercado.

Palavras-chave: Estudo de Evento; Modelo de Mercado, Variância.

\section{ABSTRACT}

In this research, it was analysed the interaction between accounting profits and the timing of profits distribution and payment to shareholders, using the abnormal accumulated return calculated through the Market Model (Ball and Brown, 1968) and by the variance of the abnormal return (Beaver, 1968). Timing means the "moment" when the disclosure or payment of remuneration to shareholders occurred: during the current year or after the disclosure of the results for the year. With this, we look for evidence of the impact of the profit distribution and payment on the informativeness of the accounting profits. The methodology of event study was applied in a sample containing 832 events of companies listed at B3, covering firms' results from 2011 to 2017. Evidences indicate that the timing of dividend annoucement is more relevant than the timing of payment the payment and it is in line with the Efficient Markets Hypothesis. The findings also suggest that the variance of the abnormal return makes it possible to identify the impact of the new information on stock prices more clearly than by the cumulative abnormal return calculated by the Market Model.

Keywords: Event Study; Market Model, Variance.

\begin{abstract}
João José Ferreira Simões
Doutorando em Administração, linha de pesquisa em Finanças, na Universidade Federal de Minas Gerais (UFMG) tendo recentemente concluído seu doutorado sanduíche na Technische Universität Braunschweig, em Braunschweig, Alemanha. Metre em Ciências Contábeis pela Universidade Federal do Espírito Santo (UFES). MBA em Mercado Financeiro e Investimentos pela FUCAPE, Espírito Santo. Graduado em Ciências Econômicas pela Universidade Vila Velha (UVV), Espírito Santo. Atualmente é pesquisador NEGEC da Universidade Federal de Minas Gerais e Revisor de periódico da Revista Eletrônica Gestão e Sociedade. Tem experiência na área de Economia, com ênfase em Investimento e Mercado Financeiro. Contato: R. São Paulo 1890 apto 301, Praia da Costa, Vila Velha-ES CEP 29.101-300. Email: simoes.joao@yahoo.com.br
\end{abstract}

\section{Antônio Artur de Souza}

Pós-doutor em Finanças pela Universidade de Grenoble (2017), França. Doutor em Management Science pela Universidade de Lancaster (1995), Inglaterra. Mestre em Engenharia de Produção também pela Universidade Federal de Santa Catarina (1990). Bacharel em Ciências Contábeis pela Universidade Federal de Santa Catarina (1987). Atualmente é professor titular da Universidade Federal de Minas Gerais. Contato: Universidade Federal de Minas Gerais, Faculdade de Ciências Econômicas, Departamento de Ciências Administrativas. Av. Antônio Carlos Pampulha, CEP 31.270901, Belo Horizonte-MG. Email: antonioarturdesouza@gmail.com

\section{Gilmar Gomes Gazzoni Junior}

Doutorando em Administração pela Universidade Federal do Espírito Santo (UFES). Mestre em Ciências Contábeis pela Universidade

Federal do Espírito Santo (UFES). Especialista em Gestão financeira, Controladoria, Perícia e Auditoria pela Faculdade Brasileira -

Multivix. Graduado em Ciências Contábeis pela Universidade Federal do Espírito Santo (UFES). Contato: Universidade Federal do Espírito Santo-CCJE, Av. Fernando Ferrari, 1358, Boa Vista, CEP 29075-505, Vitoria, ES. E-mail: jrgazoni@gmail.com

\section{Alfredo Sarlo Neto}

Doutor em Ciências Contábeis pela Universidade de São Paulo (USP). Mestre em Contabilidade pela FUCAPE. MBA em Finanças e Mercado de Capitais pelo IBMEC. Especialista em Comércio Exterio pela UFES. Graduado em Ciências Contábeis pela UFES. Atualmente é professor adjunto da Universidade Federal do Espírito Santo (UFES), lecionando para os cursos de graduação, pós-graduação e mestrado. Contato: Universidade Federal do Espírito Santo-CCJE, Av. Fernando Ferrari, 1358, Boa Vista, CEP 29075-505, Vitoria, ES E-mail: supersarloneto@gmail.com 


\section{INTRODUÇÃO}

Os trabalhos seminais de Ball e Brown (1968) e Beaver (1968) iniciaram de forma mais intensa as pesquisas com foco no conteúdo informativo das variáveis contábeis investigando a relação de variáveis contábeis e o mercado. Desde então, o impacto da divulgação de informações ao mercado de capitais é continuamente estudado no meio acadêmico. Miller e Modigliani (1961) argumentam que, em mercados perfeitos e completos, a política de dividendos não afetaria o valor da empresa, pois os investidores seriam indiferentes em receber a remuneração pelo capital investido na forma de dividendos ou de ganho de capital, sendo irrelevante a política de dividendos.

Contudo, Lintner (1962) demonstra em seu estudo que a política de dividendos é relevante, pois os investidores teriam preferência em receber os dividendos ao invés do ganho de capital, o que possibilita a redução do risco. Na mesma linha de raciocínio, Kronbauer, Lopes, Barbosa e Schwerz (2015) afirmam que a empresa pode sinalizar uma informação ao mercado por meio de sua política de dividendos, sendo o volume a ser distribuído, uma representação da expectativa do retorno esperado aos investidores. Dessa forma, os dividendos podem ser utilizados como uma ferramenta para reduzir os problemas de agência entre administradores e acionistas, o que proporciona aumento ao valor da empresa (La Porta, Lopez-de-Silanes, Shleifer, \& Vishny, 2000; Neto \& Saito, 2003).

Entende-se que os lucros podem sofrer influência dos procedimentos contábeis adotados pela empresa, sugerindo aos investidores a análise de outras variáveis como os dividendos (Brugni, Sarlo, Bastianello, \& Paris, 2012). Entretanto, existem ambientes nos quais é possível notar a realização de distribuições antecipadas dos lucros, como ocorre no Brasil, por meio da distribuição de lucros na forma de Juros Sobre o Capital Próprio (JSCP) e/ou dividendos antecipados. A política de distribuição dos lucros no Brasil diferencia-se das adotadas em outros países, pois a legislação societária e tributária permite que a remuneração seja efetuada de duas formas: por dividendos (Lei n. 6.404, 1976, art. 202) e por JSCP (Lei n. 9.249, 1995, art. 9). Assim sendo, a informatividade da distribuição dos resultados no Brasil pode ser diferente da observada em outros países, devido à legislação brasileira que regulamenta o tema.

Nesse sentido, os lucros podem ser distribuídos por meio de dividendos e de JSCP durante o exercício corrente ou após a divulgação dos resultados. Conforme Miller e Rock (1985), o anúncio do dividendo é formado por uma parcela de surpresa não esperada pelo mercado - informação nova - e uma parcela de valor esperado, já assimilada pelo mercado - informação conhecida. O lucro distribuído durante o exercício corrente torna-se uma informação conhecida e absorvida pelo mercado, o que pode reduzir o conteúdo informativo das empresas que efetuam a distribuição durante o exercício corrente, uma vez que parte da informação contida no resultado do exercício poderia ter sido absorvida. Ou seja, a tempestividade que, segundo Silva, Souza e Klann (2016), entende-se pelo momento em que a informação se torna disponível aos gestores, pode afetar a informatividade da distribuição dos lucros. Dessa forma, poderia ocorrer uma redução da surpresa contida na divulgação do lucro no resultado do exercício, surgindo a seguinte questão de pesquisa: $\mathbf{A}$ tempestividade da distribuição dos lucros do exercício tem impacto na informatividade do lucro contábil?

Devido à possibilidade existente no mercado brasileiro, a distribuição dos lucros também pode ocorrer por meio do instrumento de juros sobre capital próprio e ainda, pela distribuição antecipada de dividendos, levando ao mercado, de forma antecipada parte da informação que pode estar contida na divulgação dos dividendos. Dessa forma, este trabalho tem como objetivo geral analisar a interação entre o lucro contábil e a tempestividade da "divulgação" e do "pagamento" dos lucros aos acionistas, utilizando tanto o retorno anormal acumulado calculado através do Modelo de Mercado (Ball \& Brown, 1968), quanto a variância do retorno anormal (Beaver, 1968), contribuindo para a identificação do impacto da nova informação ao preço das ações.

A relevância e a informatividade da distribuição de dividendos têm sido discutidas na literatura internacional de finanças (Booth \& Zhou, 2017; Isibor, Modebe, Okoye, \& Ado, 2017; Dang, 2019; Nel \& Wesson, 2019), mas podem não possuir o mesmo poder explicativo quando aplicadas à realidade brasileira em virtude da (i) possibilidade de a distribuição no Brasil poder ser efetuada por meio de dividendos e JSCP e (ii) devido a legislação tributária brasileira que isenta a distribuição dos dividendos de imposto de renda (IR). Além disso, em um número restrito de países onde é observado um mecanismo considerado similar ao JSCP brasileiro - a allowance for corporate equity (ACE), traduzida de forma livre como subsídio ao capital próprio - não foram identificadas pesquisas na literatura internacional considerando o estudo desse instrumento para a relevância e a informatividade da distribuição dos lucros. Importante destacar que Israel já utilizava uma dedução ao capital próprio desde 1982, tendo sido adotado posteriormente de forma similar na Croácia, na Itália, na Áustria, na Bélgica, na Letônia e em Portugal (Simões, 2017). Nesse contexto, o presente estudo contribui ao analisar a informatividade da distribuição de dividendos no mercado brasileiro, considerando a tempestividade da distribuição dos lucros de tais empresas na forma de dividendos e/ou JSCP.

\section{FUNDAMENTAÇÃO TEÓRICA}

\subsection{A Informatividade dos Lucros Contábeis}

Ao discorrer sobre a eficiência dos mercados, Fama (1970) ressaltou que, em um mercado eficiente, os preços refletem toda a informação disponível. De acordo com Kothari (2001), um mercado eficiente incorpora instantaneamente as informações que influenciam as expectativas de fluxos de caixa líquido futuros, pois tem o poder de alterar os valores dos 
ativos negociados. Conforme o entendimento de Fama (1970), o maior objetivo de ser estudada a eficiência do mercado são os seus efeitos sobre a formação do preço. Assim, para que se tenha um mercado eficiente, torna-se imprescindível que toda a informação disponível seja absorvida aos preços dos títulos, contribuindo para responder o problema de pesquisa apresentado, em razão do impacto da nova informação que se torna disponível ao mercado.

A informatividade dos lucros contábeis tem sido objeto de estudo e visa aumentar o poder explicativo da relação entre a contabilidade e o mercado de capitais, pois, de acordo com Beaver (1968), acredita-se que o lucro seja a informação mais importante das demonstrações financeiras. Miller e Rock (1985) complementam afirmando que a divulgação de uma informação diferente da expectativa do mercado dispara um gatilho de ajuste no preço das ações. Dessa forma, na medida em que ocorrem distribuições de lucros durante o exercício corrente, o mercado tenderia a fazer o ajuste da estimativa do lucro esperado para o período, de modo a reduzir a informatividade do lucro no momento da divulgação do resultado do exercício. Miller e Rock (1985) complementam ao afirmar que o anúncio do dividendo é composto por uma parte correspondente ao valor esperado pelo mercado e por outra parte que seria equivalente à surpresa da divulgação do dividendo. Então, quanto maior a surpresa, maior deveria ser o impacto no preço das ações.

Enquanto Beaver (1968) investigou a informatividade dos lucros contábeis através da análise da reação dos investidores à divulgação dos lucros, na forma das alterações do preço e do volume das ações em semanas próximas à divulgação, Ball e Brown (1968) observaram que o lucro líquido funciona como um dos critérios no processo de tomada de decisão dos investidores. Em seu trabalho seminal, estes autores encontraram evidências de que a divulgação dos resultados anuais pode impactar o preço das ações. Todavia, outras variáveis poderiam ter influência sobre as decisões dos investidores, como o sistema financeiro, a cultura e a forma como as instituições se organizam em cada país (Booth $\&$ Zhou, 2017). Portanto, essa pesquisa visa acrescentar à literatura sobre a informatividade dos lucros contábeis quanto à tempestividade da distribuição dos lucros

\subsection{As Formas de Remuneração ao Acionista no Brasil}

No Brasil, os acionistas podem ser remunerados por meio de dividendos (Lei n. 6.404, 1976, art. 202) e de Juros Sobre o Capital Próprio (JSCP) (Lei n. 9.249, 1995, art. 9). Enquanto os dividendos são originados do lucro, conforme artigo 202 da Lei 6.404 (1976), os JSCP são calculados sobre o patrimônio líquido da empresa e classificados como despesa financeira, conforme artigo 9 da Lei 9.249 (1995), proporcionando benefício fiscal à empresa. Entretanto, os dividendos podem aumentar a capacidade informacional do lucro contábil na medida em que podem fornecer indícios sobre o desempenho futuro da firma. Conforme Miller e Rock (1985, p. 1037), o anúncio do dividendo é a última informação para os mercados tomarem conhecimento do lucro corrente da empresa, que servirá de base para estimar os lucros futuros.

Em sua pesquisa Bhattacharya (1979) encontrou evidências de que os dividendos reduzem a assimetria informacional, uma vez que sinalizam a expectativa do fluxo de caixa futuro da empresa. Por sua vez, Ofer e Siegel (1987) encontraram evidências de que os analistas modificam as expectativas de lucros futuros na mesma direção e grandeza aos anúncios de mudanças inesperadas dos dividendos. Esses autores também encontraram evidências de que estes anúncios estão relacionados positivamente às mudanças do valor dos ativos em períodos próximos ao anúncio. Entretanto, Budagaga (2017) observou uma relação positiva entre o pagamento de dividendos e o valor das empresas listadas na bolsa de Istambul, enquanto Jiang, Ma e Shi (2017) encontraram evidências de uma relação positiva entre a distribuição de dividendos e a liquidez das empresas em mercados onde o ambiente informacional não é desenvolvido.

O JSCP é fundamentado, de acordo com Brugni, Neto, Bastianello e Paris (2012), como uma remuneração ao acionista em função da indisponibilidade do recurso que foi investido na empresa, ao contrário da fundamentação dos dividendos, que ocorrem devido à existência dos lucros obtidos pela atividade empresarial. O montante a ser distribuído aos acionistas como JSCP é calculado pela taxa de juros sobre o capital próprio definida pela empresa, desde que não exceda à variação pro rata da Taxa de Juros de Longo Prazo (TJLP) (i) aplicando a Taxa de Juros de Longo Prazo (TJLP) nas contas do patrimônio líquido da empresa e (ii) limitada ao maior valor entre $50 \%$ do lucro líquido do exercício (antes da dedução dos juros) ou 50\% da soma do lucro acumulado e da reserva de lucro. Então, o valor máximo para remunerar o acionista através do JSCP é uma informação disponível ao mercado em função de seu cálculo. Com relação à questão tributária, no JSCP a tributação acontece na pessoa física com IRRF de 15\%, enquanto nos dividendos a tributação acontece na pessoa jurídica pela tributação do resultado da atividade econômica. Entretanto, o fato de a legislação permitir que o JSCP seja atribuído ao dividendo mínimo estatutário não muda a essência desses dois instrumentos, pois o JSCP pode ser imputado ao dividendo, mas não o transforma.

Em um estudo abrangendo duas empresas aéreas brasileiras, Fagundes e Petri (2017) encontraram evidências da não utilização do JSCP pelas companhias aéreas estudadas, o que teria representado uma economia de U\$38 milhões, o que sugere uma não otimização do planejamento tributário. Entretanto, a proposta para deduzir uma taxa de juros que remunerasse o capital próprio já existia desde a década de 80, com o surgimento da base teórica da allowance for corporate equity (ACE), traduzida de forma livre como subsídio ao capital próprio. Israel já utilizava uma dedução ao capital próprio desde 1982, além da Croácia (de 1994 a 2000), da Itália (de 1997 a 2003 e reiniciou em 2011), da Áustria (de 200 a 2004), da Bélgica (iniciou em 2005), da Letônia (iniciou em 2009) e de Portugal (iniciou em 2017) (Simões, 2017).

Todavia, a distribuição dos lucros não ocorre somente após a divulgação do resultado do exercício. O mercado brasileiro, segundo Lopes, Sant’Anna e Costa (2007), possui algumas características que o distingue de outros países 
como a volatilidade do mercado, a presença forte do Estado, o excesso de regulamentação contábil e a fraca proteção aos acionistas. Diante disso, as empresas são motivadas a efetuar a distribuição de lucros antes da divulgação do resultado do exercício, como forma de tornar o mercado brasileiro mais atrativo aos investidores.

\section{HIPÓTESE DE PESQUISA}

Simões (2017) encontrou evidências divergentes em sua pesquisa utilizando a metodologia de estudo de evento, na medida em que o grupo Informação Nova apresentou a média do retorno anormal acumulado inferior ao grupo Informação Conhecida. Conforme a hipótese dos mercados eficientes, em um mercado com nível de eficiência na forma fraca, a divulgação da informação poderia não impactar o preço das ações. Entretanto, esse pode não ser o caso no Brasil. Existe a possibilidade de que o impacto no preço das ações ocorra no momento do "pagamento" da remuneração aos acionistas (pagamento aos acionistas do lucro de determinado exercício) e não no momento da "divulgação" do dividendo a ser distribuído (declaração da empresa do montante do lucro a ser distribuído aos acionistas). Até mesmo porque, em um país como o Brasil, que está sujeito a alterações no cenário macroeconômico em virtude tanto da globalização da economia, quanto da situação econômica e da política interna, os acionistas poderiam esperar a concretização do pagamento da remuneração aos acionistas para realizarem ajustes em suas expectativas.

Entretanto, Ball e Brown (1968) afirmam que, ao ser divulgada uma informação relevante ao mercado, os preços das ações serão ajustados rapidamente de forma a não proporcionar ganhos anormais, caso a informação seja relevante. Michaely, Thaler e Womack (1995) encontraram evidências de que, ao decidir por remunerar os investidores em montante diferente da expectativa do mercado, os preços das ações seguem na mesma direção da mudança proposta por três trimestres, principalmente nos dias próximos à divulgação da nova informação.

Entretanto, existe a possibilidade de as empresas realizarem o pagamento do lucro aos acionistas durante o exercício corrente, ou seja, antes do protocolo do resultado do exercício na Comissão de Valores Mobiliários (CVM). Dessa forma, a informação desse pagamento naturalmente passa a ser de conhecimento do mercado, podendo reduzir o elemento surpresa que pode existir no momento da divulgação dos lucros do resultado do exercício. Assim, a informatividade da divulgação da remuneração aos acionistas (distribuição dos lucros aos acionistas) pode ter sua relevância alterada. De acordo com Beaver (1968), no momento da divulgação do lucro anual, qualquer informação relevante já teria sido processada pelos investidores e estaria refletida no preço das ações. Apresenta-se a primeira hipótese:

H1: A tempestividade da "divulgação" da distribuição de lucros é mais relevante à informatividade dos lucros contábeis do que a tempestividade do "pagamento".

Ressalta-se que, para responder essa hipótese de pesquisa será analisado o impacto da tempestividade da distribuição, considerando as duas formas encontradas na literatura: (i) o retorno anormal calculado pelo Modelo de Mercado (Ball \& Brown, 1968) e (ii) pelo estudo da variância do retorno anormal (Beaver, 1968).

Pelo Modelo de Mercado de Ball e Brown (1968), pode-se calcular o retorno esperado de uma empresa através dos parâmetros obtidos na janela de estimação do estudo de evento. Assim, é possível mensurar o retorno da empresa caso as condições do mercado fossem as mesmas. Ao subtrair o retorno observado pelo retorno esperado, obtém-se o retorno anormal que, de acordo com Campbell, Lo e MacKinlay (1997), é o pilar de um estudo de evento. O retorno anormal é, simplificadamente, um reflexo do sentimento do mercado durante a janela de estimação. Caso o mercado esteja em alta, o retorno esperado provavelmente terá um viés de alta, resultando em um retorno anormal menor do que se o mercado estivesse em baixa. Então, para um determinado retorno observado, o retorno anormal poderia não capturar ou enviesar o impacto da informatividade do lucro contábil, uma vez que estaria refletindo o impacto da divulgação de uma informação para um determinado sentimento de mercado, ocorrido durante a janela de estimação, que pode não ter se mantido na janela do evento.

Esse problema pode ser solucionado utilizando a variabilidade do preço das ações, pois, conforme Beaver (1968), a variabilidade do preço das ações é provavelmente maior ao anúncio dos lucros do que em outra época do ano, levando os investidores a efetuarem ajustes em seus portfólios. Beaver (1968) afirma que os ajustes realizados podem refletir o sentimento dos investidores de forma isolada, não alterando o preço das ações de determinada empresa, assim como, podem refletir as expectativas do mercado como um todo, ajustando o preço das ações. Assim, apresenta-se hipótese de pesquisa:

H2: A variância do retorno anormal é mais eficiente em capturar a relevância da informatividade da distribuição da remuneração aos acionistas do que o retorno anormal calculado pelo Modelo de Mercado.

Dessa forma, ao investigar o impacto da informatividade da distribuição da remuneração aos acionistas, não há a necessidade, de acordo com o exposto por Beaver (1968), que ocorra uma mudança no preço das ações, mas um aumento na variabilidade dos preços em relação a outra época do ano, que seria suficiente para sugerir que os investidores estariam efetuando ajustes em seu portfólio em função da nova informação disponibilizada ao mercado. 


\section{METODOLOGIA}

Nesta pesquisa, foi investigado o impacto causado pela tempestividade da "divulgação" da remuneração aos acionistas, assim como pela tempestividade do "pagamento", pois é comum as empresas efetuarem a distribuição dos lucros aos acionistas tanto durante o exercício corrente, quanto após a divulgação do resultado do exercício. Foi realizado um estudo com objetivo de verificar a ocorrência de impacto no preço das ações em função da tempestividade da "divulgação" da distribuição da remuneração aos acionistas e outro estudo em função da tempestividade do "pagamento". Por tempestividade, entende-se o momento em que ocorreu a divulgação ou o pagamento da remuneração aos acionistas: durante o exercício corrente ou após a divulgação do resultado do exercício. Foi aplicada a metodologia de estudo de evento com utilização dos softwares Stata e Microsoft Excel.

Nas pesquisas em Contabilidade e Finanças observa-se a utilização da metodologia de estudo de eventos desde o artigo seminal de Ball e Brown (1968). Entretanto, apesar de não ser uma metodologia inovadora, Fama (1991) afirma que o estudo de evento é a metodologia mais apropriada para se estudar a eficiência dos mercados. Pesquisas recentes em renomados periódicos internacionais podem validar a aplicabilidade e a eficiência de um estudo de evento, como Ederington, Guan e Yang (2015), Lin, Morck, Yeung e Zhao (2016), Thornton (2017) e Loipersberger (2018).

\subsection{Coleta de Dados e Amostra}

As empresas de capital aberto podem divulgar os lucros a distribuir ou efetivamente distribuí-los durante o exercício corrente, conforme figura 1, tornando essa informação conhecida ao mercado. Do mesmo modo, podem fazer a divulgação do lucro a ser distribuído na divulgação do resultado do exercício, levando ao mercado uma informação nova.

Figura 1 - Descrição da distribuição da remuneração aos acionistas do exercício de 20X0.

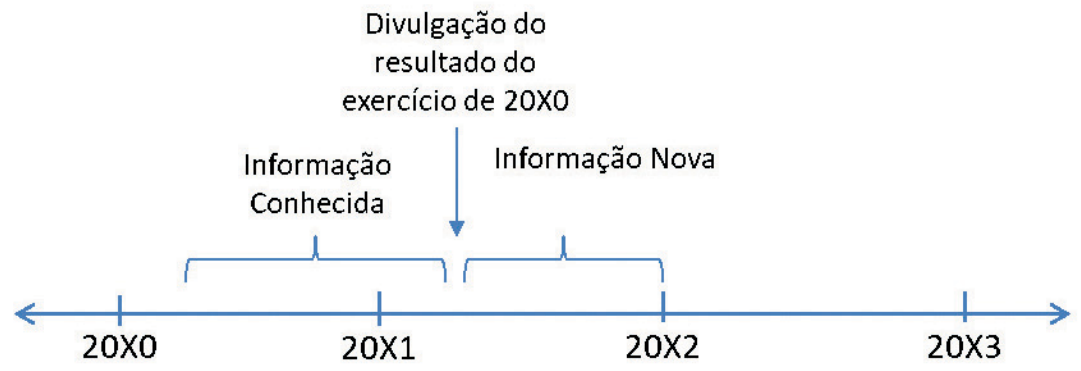

Fonte: Adaptado de Simões (2017).

Foi pesquisado em uma amostra contendo 832 eventos o impacto da tempestividade da "divulgação" e do "pagamento" da remuneração aos acionistas no preço das ações das empresas listadas na B3, que divulgaram seus resultados no período de 2011 a 2017 (exercícios de 2010 a 2016). As pesquisas sobre a distribuição dos lucros aos acionistas são, em grande parte, realizadas no mercado americano. Entretanto, a realidade do mercado brasileiro é diferente em função da existência do JSCP, podendo influenciar a informatividade da distribuição dos resultados. Justifica-se, assim, a escolha por empresas listadas na bolsa de valores de São Paulo (B3 Brasil Bolsa Balcão). Os dados foram obtidos através da base de dados comdinheiro.com e nas demonstrações financeiras das empresas. No caso de uma empresa ter mais de uma classe de ações, foi escolhida a classe que apresentava maior liquidez.

\subsection{Definição de Evento}

Nesta pesquisa, a data da divulgação das demonstrações contábeis protocoladas na CVM é considerada como a data do evento. Nela é informada a proposta de distribuição aos acionistas dos lucros do exercício que será levada para votação na Assembleia Geral. Em um estudo de evento, devem ser especificadas as janelas de estimação e do evento. A janela de estimação é o período em que são observados os parâmetros $\alpha$ e $\beta$ para elaborar as estimações necessárias. Por sua vez, a janela do evento, que é o período utilizado para verificar se houve impacto pela ocorrência do evento, compreende em 10 dias antes do evento (dia -10) até 20 dias após o evento (dia +20). Assim, o período de cada estudo de evento perfaz uma amplitude de 121 dias, conforme pode ser observado na figura 2. O tamanho das janelas de estimação e do evento é definida de forma arbitrária, entretanto, não é desejável que os períodos sejam muito longos de forma a evitar a interferência de outros fatores que possam causar impacto no preço das ações (Neto \& Saito, 2003). 
Figura 2 - Linha do tempo do evento

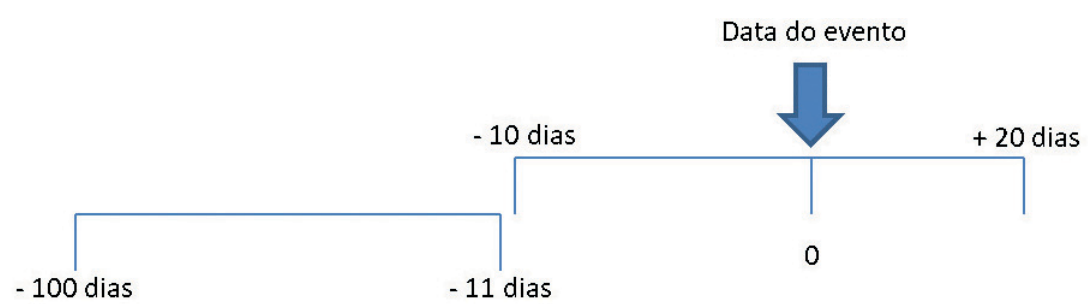

Fonte: Simões (2017)

De acordo com Fama (1991), em um estudo de evento é possível ter uma noção da velocidade em que ocorrem os ajustes nos preços das ações quando uma informação nova é divulgada.

\subsection{Modelo de Mercado}

O Modelo de Mercado (Ball \& Brown, 1968) é "uma regressão linear entre os retornos $r_{i}$ de uma determinada ação e os retornos da carteira de mercado $r_{m}$ " (Sarlo, Teixeira, Loss, \& Lopes, 2005) e será utilizado para o cálculo do retorno anormal em cada evento. Através desse modelo, podemos estimar qual seria o retorno da empresa i no período $\mathrm{t}$, com base nos parâmetros $\alpha$ e $\beta$ verificados na janela de observação do evento, se as condições do mercado fossem as mesmas. Onde: $r_{i, t}$ é o retorno da empresa i na data t; $\alpha$ é o intercepto da empresa i; $\beta$ é o parâmetro da inclinação da empresa i; $r_{i, t}$ é retorno do mercado na data t; e é o erro da empresa i, na data t, e como proxy para o retorno de mercado será considerado o retorno da carteira teórica do Ibovespa.

$$
r_{i, t}=\alpha_{i}+\beta_{i} r_{m, t}+e_{i, t}
$$

Através do intercepto $\alpha$ e do coeficiente de variação $\beta$ obtidos pelo Modelo de Mercado na janela de estimação do evento, podemos calcular o retorno esperado - $\mathrm{E}(\mathrm{r})$. De uma forma geral, o retorno esperado seria o retorno obtido pelo investimento caso as condições do mercado se mantivessem como aquela observada na janela de estimação do evento, que parte do intervalo de -100 dias até -11 dias antes do evento. Onde: $\mathrm{E}($ ) é o retorno esperado da empresa i na data t; $\alpha$ é o parâmetro do intercepto da empresa i; $\beta$ é o coeficiente da variação da empresa i; é retorno do mercado na data t.

$$
\mathrm{E}\left(r_{i, t}\right)=\alpha_{i}+\beta_{i} r_{m, t}
$$

O retorno anormal é a diferença entre o retorno observado da ação da empresa i, no período t, pelo retorno esperado da mesma empresa no período t, sendo que, conforme Campbell et al. (1997), o cálculo do retorno anormal é o ponto de sustentação de um estudo de evento. Então, o retorno anormal pode ser considerado como o retorno obtido em excesso ao retorno que esperava-se obter caso as condições do mercado permanecessem as mesmas. Onde: $u_{i, t}$ é o retorno anormal da empresa i na data t; $r_{i, t}$ é o retorno observado da empresa i no período t; $E\left(r_{i, t}\right)$ é o retorno esperado da empresa i no período t.

$u_{i, t}=r_{i, t}-E\left(r_{i, t}\right)$

Em seguida, os retornos anormais devem ser capitalizados diariamente, resultando no retorno anormal. Dessa forma, pode ser demonstrada a trajetória do preço da ação de uma empresa no período da janela estudada, antes e depois da divulgação do evento (Sarlo Neto et al., 2005).

$C A R_{i, t}=\prod_{t=-10}^{T}\left(1+u_{i, t}\right)-1$

\subsection{Variância do Retorno Anormal}

Será aplicada a metodologia de Beaver (1968) para o estudo da variância do retorno anormal, visando verificar o impacto da tempestividade tanto da divulgação, quanto do pagamento da remuneração aos acionistas. Conforme Beaver (1968), a divulgação do lucro apresenta conteúdo informacional caso seja alterada a percepção do investidor quanto à distribuição de probabilidade dos lucros futuros. Dessa forma, a variabilidade da mudança dos preços é provavelmente maior quando os lucros são anunciados do que em outra época do ano, com a ocorrência de uma maior magnitude na variação do preço das ações. 
O termo $u_{i, t}$ relativo ao retorno anormal é elevado ao quadrado $\left(u_{i, t}^{2}\right)$ para abstrair seu sinal, pois o objetivo é investigar o tamanho da variabilidade, e não sua direção. Espera-se que o termo $u_{i, t}^{2}$ seja maior nos dias seguintes à divulgação do lucro. Conforme Beaver (1968) a relação do termo $u_{i, t}^{2}$ nos dias seguintes à divulgação do resultado do exercício e a média do período pode ser expresso pela razão $U_{i, t}$, onde $u_{i, t}^{2}$ é o quadrado do termo de erro da empresa i na data t; $S_{i}^{2}$ é a variância do retorno anormal da empresa i na janela do evento; $U_{i, t}$ é a magnitude do retorno anormal. Quanto mais $U_{i, t}>$, maior será a magnitude da mudança do preço das ações.

$$
U_{i, t}=\frac{u_{i, t}^{2}}{s_{i}^{2}}
$$

De acordo com Sarlo, Lopes e Costa (2008), quando o anúncio das informações contábeis não possuírem conteúdo informacional, a magnitude do retorno anormal será 1, pois não haverá alteração no preço das ações. Assim, considera-se o índice para a magnitude como o índice médio da magnitude da variância do retorno anormal para cada grupo estudado. Onde: $U_{i, t}$ é a magnitude da variância do retorno anormal da empresa i na data t: $\bar{U}_{g, t}$ é a média da magnitude da variância do retorno anormal das empresas do grupo g; n é o número de empresas do grupo.

$$
\bar{U}_{g, t}=\frac{1}{n} \sum_{q=1}^{n} U_{i, t}
$$

\section{PROCEDIMENTOS}

A amostra de trabalho composta por 832 eventos foi dividida em três grupos: (i) Informação Nova, (ii) Informação Conhecida e (iii) Ambos, este último composto por empresas que distribuíram de ambas as formas (antes e depois da divulgação do resultado do exercício). É assumido como premissa desta pesquisa que os eventos são independentes. Foi observado o comportamento das ações das empresas de cada grupo na janela de estimação para que fosse calculado o retorno anormal pelo Modelo de Mercado (Ball \& Brown, 1968) e a variância do retorno anormal (Beaver, 1968), visando identificar o impacto da tempestividade tanto da divulgação da distribuição da remuneração aos acionistas como do efetivo pagamento.

\subsection{A Tempestividade da "Divulgação" da Distribuição da Remuneração aos Acionistas}

O grupo "Informação Nova” foi formado pelos eventos das empresas que divulgaram a distribuição do lucro juntamente com a divulgação do resultado do exercício, não tendo ocorrido divulgação durante o exercício. Entende-se que, na divulgação do resultado do exercício, foi levado ao conhecimento do mercado uma informação nova, pois não houve nenhuma outra divulgação de distribuição de remuneração aos acionistas durante o exercício corrente.

O grupo "Informação Conhecida" foi formado pelos eventos das empresas que divulgaram a totalidade da distribuição da remuneração aos acionistas durante o exercício corrente. Desse modo, quando ocorreu a divulgação do resultado do exercício, as empresas desse grupo não divulgaram nenhuma distribuição complementar da remuneração aos acionistas em relação ao que já havia sido divulgado durante o exercício corrente. Então, quando foi divulgado o lucro do exercício, não houve divulgação de informação nova a respeito da remuneração aos acionistas, uma vez que todo o valor a ser distribuído já havia sido informado ao mercado, provavelmente reduzindo a relevância da informatividade da divulgação.

Por sua vez, o grupo "Ambos" é formado por eventos de empresas com características dos dois grupos anteriores, ou seja, houve pelo menos um anúncio de distribuição de lucros aos acionistas durante o exercício corrente e houve a divulgação de distribuição de remuneração complementar no resultado do exercício. Entretanto, ressalta-se que o foco deste trabalho são os grupos Informação Nova e Informação Conhecida, uma vez que possuem características definidas se comparados ao grupo Ambos. Na tabela 1, é apresentada a descrição dos grupos da amostra. 
Tabela 1 - Descrição dos grupos da amostra considerando a tempestividade da divulgação da distribuição da remuneração aos acionistas.

\begin{tabular}{|c|c|c|c|c|c|c|}
\hline & & \multicolumn{4}{|c|}{ Remuneração Futura } & \multirow[b]{2}{*}{ Total } \\
\hline & & $\begin{array}{c}\text { Sem } \\
\text { remuneração }\end{array}$ & JSCP & Dividendos & $\begin{array}{c}\text { JSCP + } \\
\text { Dividendos }\end{array}$ & \\
\hline \multirow{4}{*}{$\begin{array}{c}\text { Remuneração } \\
\text { Passada }\end{array}$} & Sem remuneração & & 32 & 249 & 54 & 335 \\
\hline & JSCP & 58 & 35 & 86 & 33 & 212 \\
\hline & Dividendos & 34 & 6 & 71 & 8 & 119 \\
\hline & JSCP + Dividendos & 46 & 9 & 67 & 44 & 166 \\
\hline \multicolumn{2}{|c|}{ Total } & 138 & 82 & 473 & 139 & 832 \\
\hline
\end{tabular}

Onde: Remuneração Futura, refere-se ao grupo "Informação nova”; Remuneração Passada, refere-se ao grupo "Informação conhecida"; e a interseção entre ambos, refere-se ao grupo "Ambos". Fonte: Dados da pesquisa.

Na figura 3, pode ser observado o comportamento do retorno anormal acumulado dos três grupos, calculados a partir do Modelo de Mercado (Ball \& Brown, 1968). No período anterior à data do evento, enquanto os grupos Informação Nova e Informação Conhecida apresentam variação positiva, o grupo Ambos apresentam variação negativa. O comportamento do grupo Informação Nova na janela do evento tem início com uma variação positiva para então, começar a reverter a partir do dia -6. Na data do evento, o grupo Informação Conhecida apresenta um retorno anormal acumulado superior ao dos grupos Informação Nova e Ambos.

A partir da data do evento, o grupo Informação Conhecida teve variação superior aos outros grupos em todos os dias, o que é inesperado, em função de o grupo Informação Conhecida ser o grupo que divulgou as informações acerca da distribuição da remuneração aos acionistas antes da divulgação do resultado do exercício. Logo, era esperado que esse grupo não apresentasse relevância em seu conteúdo informativo.

Figura 3 - Retorno Anormal Acumulado da tempestividade da divulgação.

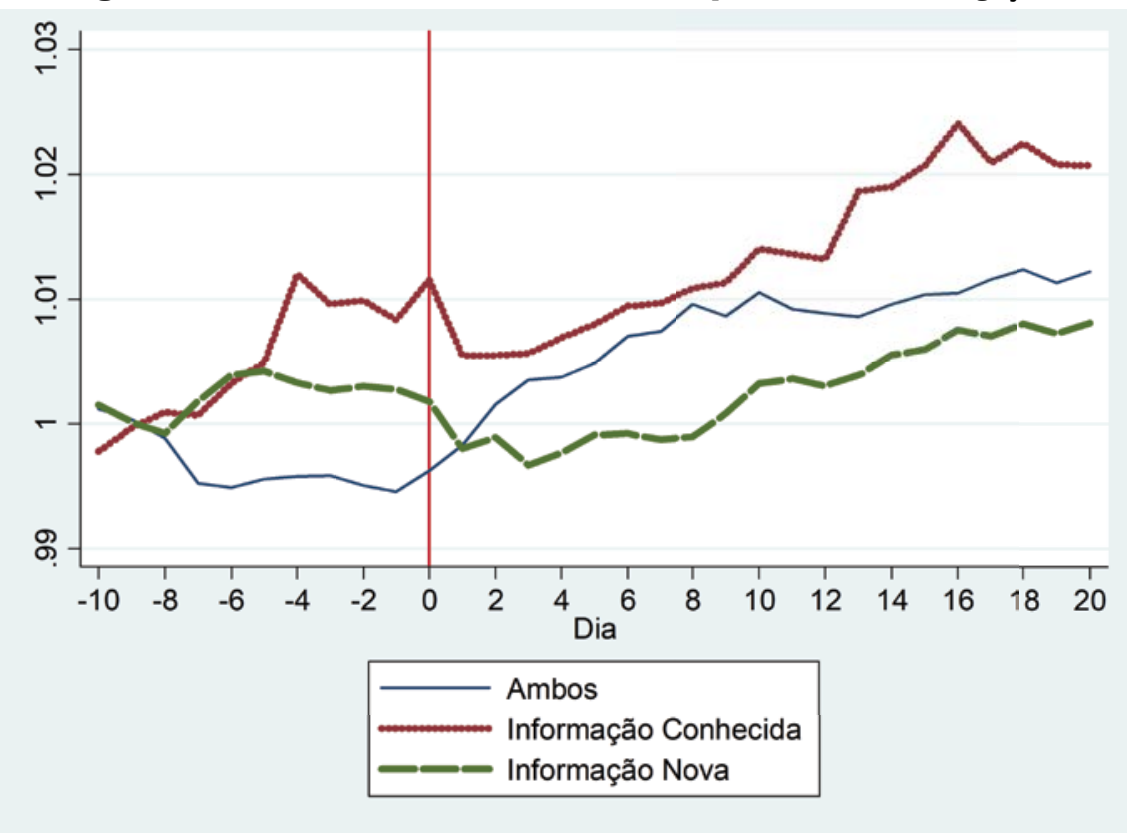

Fonte: Dados da pesquisa.

Na data do evento, os grupos Informação Nova, Informação Conhecida e Ambos apresentaram, respectivamente, retorno anormal acumulado de 1,002\%, 1,012\% e 0,996\%, com significância estatística a 10\% de confiabilidade somente para o grupo Informação Conhecida. Da data do evento até o dia 3, os grupos apresentam comportamento distinto, como se o mercado estivesse ainda assimilando as informações divulgadas, para, a partir daí, os três grupos apresentarem variação positiva em intensidades diferentes em relação ao retorno anormal acumulado. Realizado o teste t para duas amostras, foi encontrada significância estatística a 10\% de confiabilidade apontando evidências de que o retorno anormal acumulado do grupo Informação Conhecida é maior do que o grupo Informação Nova somente no dia -4 e no dia 16. 
Contudo, é importante ressaltar que, ao utilizar o Modelo de Mercado (Ball \& Brown, 1968) para calcular o retorno esperado em um estudo de evento, leva-se em conta o comportamento do mercado na janela de observação para criar uma expectativa de qual seria o retorno da empresa, caso as condições do mercado permanecessem as mesmas. Entretanto, pelo menos duas possibilidades podem ocorrer: (i) as condições do mercado não permanecerem as mesmas e (ii) o fato de que o lucro da empresa foi obtido com base em suas operações durante o ano, não tendo que estar obrigatoriamente correlacionado com o comportamento do mercado durante a janela do evento.

Portanto, é possível que o retorno esperado poderia, nesse caso, ter sido superestimado com base nas condições do mercado durante a janela de evento, se comparado com as condições macroeconômicas e setoriais enfrentadas pela empresa durante o exercício. Assim, o fato de o grupo Informação Nova ter tido um desempenho negativo logo após a data do evento pode não ser um indicativo de que não houve impacto em função da divulgação da informação, mas que o impacto pode ter sido negativo em função da uma expectativa de retorno esperado desalinhada com a realidade da empresa. A seguir, na figura 4, pode ser observado que no dia 1, os três grupos apresentaram magnitude da variância maior que 1, indicando que a divulgação do resultado do exercício apresentou conteúdo informacional relevante aos grupos Informação Nova, Informação Conhecida e Ambos, com magnitude da variância de 2,206, 2,120 e 2,104, respectivamente, todos significantes a $1 \%$.

Figura 4 - Magnitude da variância do retorno anormal da tempestividade da divulgação.

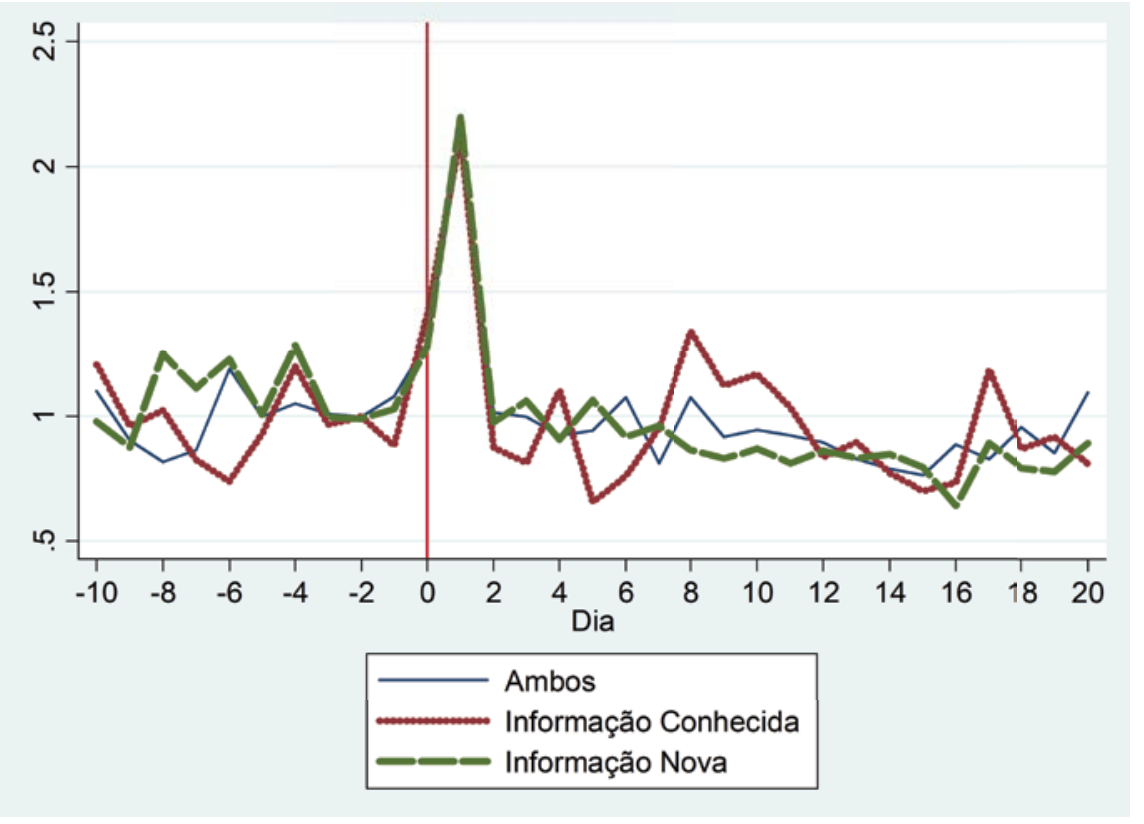

Fonte: Dados da pesquisa.

Esse resultado é condizente com a hipótese de eficiência dos mercados, uma vez que há indícios de que a informação nova causou impacto ao preço das ações, na medida em que a maior variabilidade do retorno anormal fornece indícios de que o mercado efetuou ajustes visando absorver a nova informação. Apesar disso, os outros grupos também apresentaram impacto expressivo. Após a realização do teste t para duas amostras, foi encontrada significância estatística a 5\% de que, nos dias 3 e 5 a média da magnitude da variância do retorno anormal do grupo Informação Nova é maior do que a do grupo Informação Conhecida, sugerindo evidências da relevância da informação divulgada. Entretanto, não foi encontrado significância no dia 1.

\subsection{A Tempestividade do "Pagamento" da Remuneração aos Acionistas}

Neste estudo, serão formados três grupos a partir da amostra de trabalho, mas o foco não será a tempestividade da divulgação da remuneração aos acionistas, mas da realização do pagamento da remuneração. Isto quer dizer que a formação dos grupos respeitará a condição de o pagamento da remuneração aos acionistas ter sido efetuado durante o exercício corrente ou após a divulgação do resultado do exercício. Assim, o grupo Informação Nova foi formado pelos eventos das empresas que efetuaram o pagamento da remuneração aos acionistas após a divulgação do resultado do exercício, enquanto o grupo Informação Conhecida foi formado pelos eventos das empresas que efetuaram o pagamento da totalidade da remuneração aos acionistas durante o exercício corrente. Por sua vez, como no estudo anterior, o grupo Ambos foi formado pelos eventos das empresas que tiveram as características dos grupos anteriores, tendo efetuado parte do pagamento antes do resultado do exercício e parte após. Na tabela 2, é possível observar a formação de cada grupo. 
Tabela 2 - Descrição dos grupos da amostra considerando a tempestividade do pagamento da remuneração aos acionistas.

\begin{tabular}{|c|c|c|c|c|c|c|}
\hline & \multicolumn{4}{|c|}{ Remuneração Futura } & \multirow[b]{2}{*}{ Total } \\
\hline & & $\begin{array}{c}\text { Sem } \\
\text { remuneração }\end{array}$ & JSCP & Dividendos & $\begin{array}{c}\text { JSCP + } \\
\text { Dividendos }\end{array}$ & \\
\hline \multirow{4}{*}{$\begin{array}{c}\text { Remuneração } \\
\text { Passada }\end{array}$} & Sem remuneração & & 54 & 255 & 62 & 371 \\
\hline & JSCP & 38 & 33 & 81 & 37 & 189 \\
\hline & Dividendos & 28 & 5 & 71 & 9 & 113 \\
\hline & JSCP + Dividendos & 32 & 9 & 66 & 52 & 159 \\
\hline \multicolumn{2}{|c|}{ Total } & 98 & 101 & 473 & 160 & 832 \\
\hline
\end{tabular}

Onde: Remuneração Futura, refere-se ao grupo "Informação nova”; Remuneração Passada, refere-se ao grupo "Informação conhecida"; e a interseção entre ambos, refere-se ao grupo "Ambos". Fonte: Dados da pesquisa.

Na data do evento, os grupos Informação Nova, Informação Conhecida e Ambos apresentaram, respectivamente, retorno anormal acumulado de $1,001 \%, 1,008 \%$ e 0,998\%, entretanto, nenhum deles apresentou significância estatística no teste $t$ (teste de média) realizado. Observando a figura 5, nota-se que o grupo Informação Conhecida teve variação superior ao grupo Informação Nova desde o dia -6 . Outro fato interessante com relação a este estudo é que, no teste $t$ para duas amostras não foi encontrado significância estatística de que a média do retorno anormal acumulado do grupo Informação Conhecida seja maior do que a média do grupo Informação Nova.

Figura 5 - Retorno Anormal Acumulado da tempestividade do pagamento.

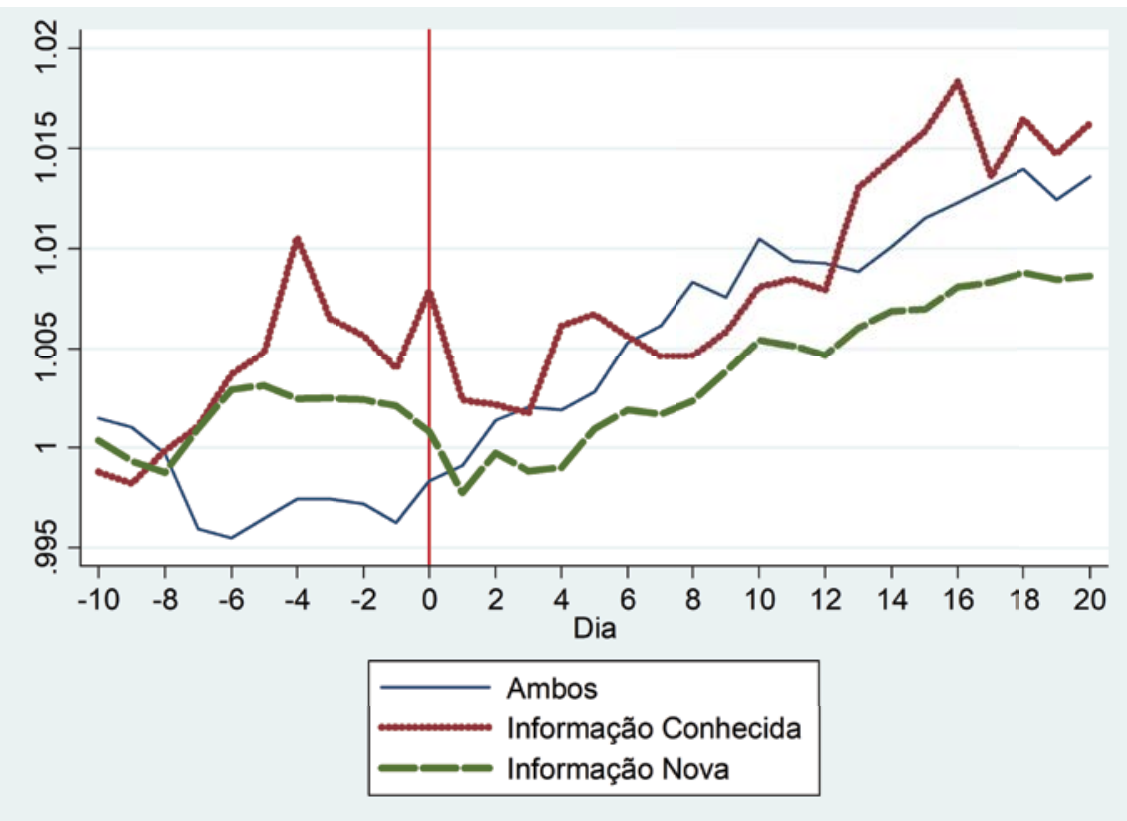

Fonte: Elaborado pelo autor (2020). 
Na figura 6, pode ser observado que no dia 1 os três grupos apresentaram a magnitude da variância maior que 1 , indicando evidências do conteúdo informacional apresentado na divulgação do resultado do exercício. Os grupos Informação Nova, Informação Conhecida e Ambos apresentaram magnitude da variância de 2,139, 1,910 e 2,170, respectivamente, todos significantes a $1 \%$, conforme o observado no estudo 5.1 .

Figura 6 - Magnitude da variância do retorno anormal da tempestividade do pagamento.

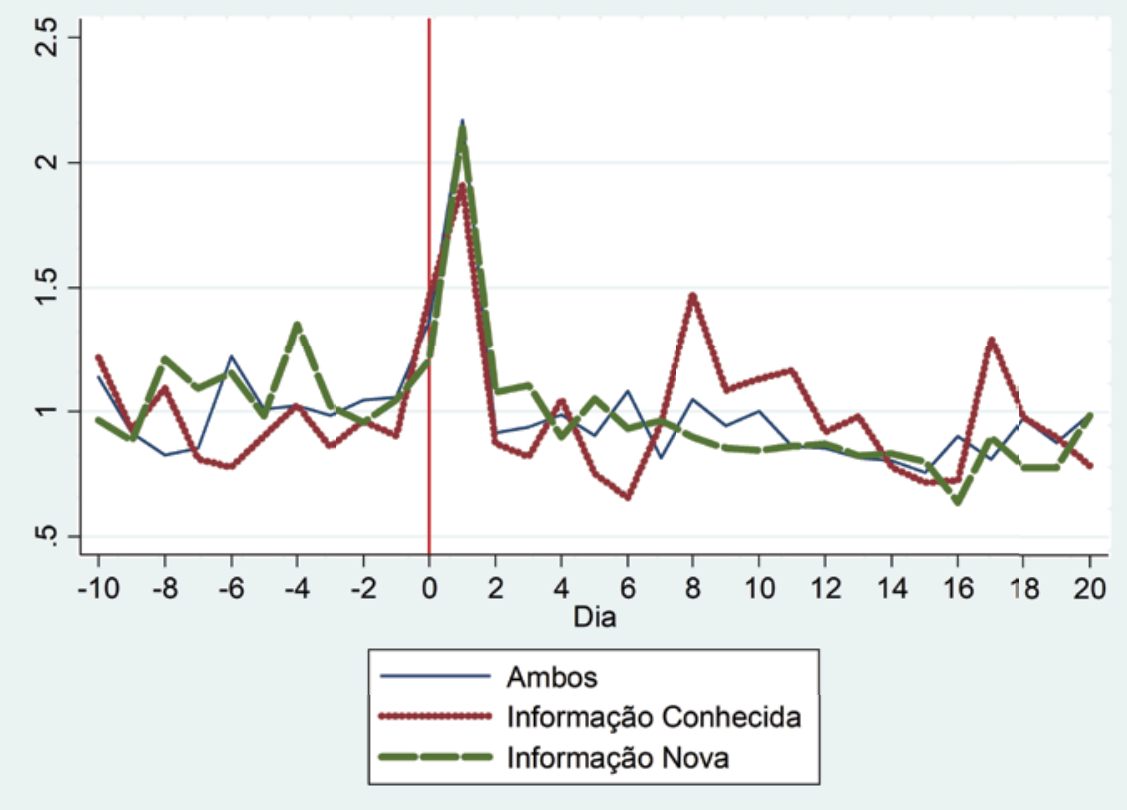

Fonte: Elaborado pelo autor (2020).

Foi inesperado o grupo Informação Conhecida ter apresentado magnitude maior que o grupo Informação Nova. Então, foi realizado um teste t de duas amostras e não foram encontradas evidências de que a média do grupo Informação Conhecida seja maior que a do grupo Informação Nova. Entretanto, nos dias 2, 3, 5 e 6, foram encontradas evidências com significância estatística a $10 \%$ de confiabilidade de que a média da magnitude da variância do retorno anormal do grupo Informação Nova é maior do que a do grupo Informação Conhecida.

\subsection{Análise dos Resultados}

Para responder as hipóteses de pesquisa $\mathrm{H} 1$ e $\mathrm{H} 2$, foram realizados estudos da tempestividade da divulgação da distribuição da remuneração aos acionistas (estudo 5.1) e o estudo da tempestividade do pagamento (estudo 5.2). Em cada estudo, foi utilizado (i) o retorno anormal acumulado calculado a partir do Modelo de Mercado (Ball \& Brown, 1968) e (i) a variância do retorno anormal (Beaver, 1968). Essas quatro análises serão utilizadas para responder as hipóteses de pesquisa.

Os estudos do retorno anormal acumulado, relatados nos itens 5.1 e 5.2, apresentaram um resultado inesperado, em função de o grupo Informação Conhecida ter apresentado variação superior ao grupo Informação Nova. Era esperado que o grupo Informação Conhecida não apresentasse impacto, em função de ser uma informação já disseminada no mercado, e que o grupo Informação Nova apresentasse impacto, uma vez que o mercado provavelmente efetuaria ajustes no preço das ações das empresas ao tomar conhecimento da nova informação. Apesar de já terem sido relatados os testes $t$ efetuados anteriormente, foi efetuado um teste t para duas amostras, na busca por evidências que pudessem indicar que o estudo da tempestividade da divulgação da distribuição dos lucros (estudo 5.1) apresentasse média do retorno anormal acumulado superior ao estudo da tempestividade do pagamento (estudo 5.2). Assim, o teste t para duas amostras comparou cada grupo do estudo 5.1 com o respectivo grupo do estudo 5.2. Não foram encontradas evidências que pudessem indicar que a média de cada grupo do estudo 5.1 fosse diferente da média do respectivo grupo do estudo 5.2. Sendo assim, não foram observadas evidências entre a tempestividade da distribuição e a tempestividade do pagamento dos lucros no preço das ações, considerando o retorno anormal acumulado.

É importante destacar que os estudos da magnitude da variância do retorno anormal apresentaram variação superior a 1 logo no primeiro dia após a data do evento. Esse resultado é condizente com os achados de Beaver (1968) e Sarlo et al. (2008), sugerindo que a divulgação de informação nova ao mercado pode provocar uma reação nos investidores quanto à percepção da geração de fluxos de caixa futuros. A mudança da percepção pode levar os investidores a realizarem ajustes em seus portfólios por meio da compra ou venda de ações. 
Além dos testes t realizados durante os estudos 5.1 e 5.2 para a magnitude da variância do retorno anormal (Beaver, 1968), foi executado um teste t para duas amostras, na busca por evidências que pudessem indicar que o estudo da tempestividade da divulgação da remuneração aos acionistas (estudo 5.1) apresentasse média da magnitude da variância do retorno anormal (Beaver, 1968) superior ao estudo da tempestividade do pagamento (estudo 5.2). O teste t para duas amostras comparou cada grupo do estudo 5.1 com o respectivo grupo do estudo 5.2. Foram encontradas evidências de que a média da magnitude da variância do estudo da tempestividade da divulgação (5.1) dos grupos Informação Nova, Informação Conhecida e Ambos é maior do que a média da magnitude da variância do respectivo grupo no estudo da tempestividade do pagamento. $O$ resultado observado, considerando o estudo da variância do retorno anormal, sugere a confirmação da hipótese de pesquisa $\mathrm{H1}$ : A tempestividade da divulgação da distribuição de lucros é mais relevante à informatividade dos lucros contábeis do que a tempestividade do pagamento. A significância estatística encontrada para a data do evento para os grupos Informação Nova, Informação Conhecida e Ambos foi de $1 \%$, $5 \%$ e 1\%, respectivamente. Para os mesmos grupos no dia 1, a significância estatística foi de $1 \%$ para todos os grupos. Esse resultado também confirma a hipótese de pesquisa H2: A variância do retorno anormal (Beaver, 1968) é mais eficiente em capturar a relevância da informatividade da distribuição da remuneração aos acionistas do que o retorno anormal calculado pelo Modelo de Mercado.

\section{CONSIDERAÇÕES FINAIS}

Neste estudo, foi analisada a interação entre o lucro contábil e a tempestividade da distribuição e do pagamento dos lucros aos acionistas, utilizando o retorno anormal acumulado calculado através do Modelo de Mercado (Ball \& Brown, 1968) e a variância do retorno anormal (Beaver, 1968). Entende-se por tempestividade o momento em que ocorreu a divulgação ou o pagamento da remuneração aos acionistas: durante o exercício corrente ou após a divulgação do resultado do exercício. A pesquisa foi realizada utilizando a metodologia de estudo de evento em uma amostra de 832 eventos de empresas listadas na B3, abrangendo a distribuição de lucros dos exercícios de 2010 a 2016.

As evidências observadas indicam que a tempestividade da distribuição do resultado do exercício tem impacto na informatividade do lucro contábil. Esses achados corroboram com aqueles de Sarlo et al. (2008) e com a relevância do lucro contábil dada a tempestividade da distribuição dos lucros aos acionistas, observada por Simões (2017). Em um número restrito de países onde é observado um mecanismo considerado similar ao JSCP brasileiro (a allowance for corporate equity - ACE), a relevância e a informatividade da distribuição de dividendos podem não possuir o mesmo poder explicativo quando aplicadas à realidade local, mas pouco tem-se estudado sobre isso. As evidências observadas nesta pesquisa abrem novas possibilidades para as pesquisas cross-countries relativas à informatividade dos lucros contábeis, não somente com relação às variáveis que possam causar impacto na distribuição do lucro, mas também, por considerar o mecanismo do JSCP como fator determinante para a relevância e a informatividade dos lucros contábeis.

As evidências observadas sugerem a confirmação da hipótese de pesquisa $\mathrm{H}$ 1, pois apontam que a magnitude da variância do retorno anormal (Beaver, 1968) do grupo Informação Nova é maior do que a do grupo Informação Conhecida. Os achados observados também indicam a confirmação da hipótese de pesquisa H2, pois a magnitude da variância do retorno anormal (Beaver, 1968) possibilita identificar o impacto da nova informação ao preço das ações de forma mais clara do que pelo retorno anormal calculado pelo Modelo de Mercado (Ball \& Brown, 1968). Conforme Beaver (1968), a magnitude da variância do retorno anormal observada está de acordo com o esperado para a divulgação dos lucros, demonstrando evidências da informatividade do lucro contábil.

As evidências sugerem que a análise pela magnitude da variância pode capturar o impacto da informação, uma vez que verifica o quanto de variabilidade ocorreu no preço da ação, independentemente do sinal da variação. Por sua vez, o retorno anormal acumulado calculado pelo Modelo de Mercado (Ball \& Brown, 1968) projeta no retorno esperado o sentimento do mercado que foi observado durante a janela de estimação, não tendo que estar obrigatoriamente relacionado com a perspectiva do resultado da empresa que será fruto de suas atividades de todo um exercício. Pelo Modelo de Mercado (Ball \& Brown, 1968), é considerado que o único fator que afeta o retorno da empresa é o retorno da carteira de mercado, enquanto que, pela análise da magnitude da variância, cada investidor reflete o impacto que a divulgação da informação proporcionou a sua tomada de decisão, independentemente da forma com que tenha sido calculado ou desenvolvido, sua expectativa quanto ao retorno esperado, além do fato de que parte da amostra pode ter tido variação positiva e parte, variação negativa.

Foi inesperado encontrar 283 eventos (aproximadamente 34\% da amostra) em que a distribuição da remuneração aos acionistas foi efetuada exclusivamente por meio de dividendos, não tendo sido utilizado o benefício fiscal proporcionado pela distribuição dos lucros por JSCP. É importante ressalvar que a metodologia de estudo de eventos não observa outras variáveis que possam influenciar as variações na cotação de uma ação, configurando-se uma limitação deste trabalho. Para futuras pesquisas é sugerido (i) um estudo incluindo o volume de ações transacionadas com vistas a aumentar a capacidade de capturar o impacto da divulgação da distribuição dos lucros e (ii) uma investigação a respeito do que levaria as empresas a não aproveitaram o benefício fiscal proporcionado pelo JSCP ao distribuir o lucro exclusivamente na forma de dividendos. 


\section{REFERÊNCIAS}

Ball, R., \& Brown, P. (1968). An empirical evaluation of accounting income numbers. Journal of accounting research, 159-178.

Beaver, W. H. (1968). The information content of annual earnings announcements. Journal of accounting research, 67-92.

Booth, L., \& Zhou, J. (2017). Dividend policy: A selective review of results from around the world. Global Finance Journal, 34, 1-15.

Brugni, T. V., Sarlo, A., Nt., Bastianello, R. F., \& Paris, P. K. S. (2012). Influência de dividendos sobre a informatividade dos lucros: evidências empíricas na BM\&FBOVESPA. Revista universo contábil, 8(3), 82-99.

Budagaga, A. (2017). Dividend payment and its impact on the value of firms listed on Istanbul stock exchange: A residual income approach. International Journal of Economics and Financial Issues, 7(2), 370.

Campbell, J. Y., Lo, A. W. C., \& MacKinlay, A. C. (1997). The econometrics of financial markets (Vol. 2, pp. 149-180). Princeton, NJ: Princeton University press.

Dang, C. (2019). An Empirical Study on the Relationship between Capital Cost and Dividend Policy of Listed Companies Based on Stock Market. $3^{a}$ International Conference on Economics, Management Engineering and Education Technology (ICEMEET 2019).

Ederington, L., Guan, W., \& Yang, L. Z. (2015). Bond market event study methods. Journal of Banking \& Finance, 58, 281-293.

Fagundes, C., \& Petri, S. M. (2017). Juros sobre capital próprio: um estudo da contribuição no resultado tributário nas empresas Gol e Latam. Revista da UNIFEBE, 1(22), 55-86.

Fama, E. F. (1970). Efficient capital markets: A review of theory and empirical work. The Journal of Finance, 25(2), 383-417.

Fama, E. F. (1991). Efficient capital markets: II. The Journal of finance, 46(5), 1575-1617.

Isibor, A. A., Modebe, N. J., Okoye, L. U., \& Ado, A. (2017). Dividend policy and value of firm: is dividend relevant or not?. ESUT JOURNAL OF ACCOUNTANCY, 8(1).

Jensen, M. C. (1986). Agency costs of free cash flow, corporate finance, and takeovers. The

Jiang, F., Ma, Y., \& Shi, B. (2017). Stock liquidity and dividend payouts. Journal of Corporate finance, 42, 295-314.

Kothari, S. P. (2001). Capital markets research in accounting. Journal of accounting and economics, 31(1-3), 105-231.

Kronbauer, C. A., Lopes, J. C. S., Barbosa, M. A. G., \& Schwerz, M. B. (2015). Uma análise dos Estudos sobre Política de Dividendos nos Periódicos Brasileiros no Período de 2007 a 2012. Revista de Ciências Jurídicas, 15(2).

La Porta, R., Lopez-de-Silanes, F., Shleifer, A., \& Vishny, R. (2000). Investor protection and corporate governance. Journal of financial economics, 58(1), 3-27.

Lei 6.404 de 15 de dezembro de 1976. (1976). Dispõe sobre as Sociedades por Ações. Recuperado de http://www.planalto.gov.br/ ccivil_03/Leis/L6404consol.htm

Lei 9.249 de 26 de dezembro de 1995. (1995). Altera a legislação do imposto de renda das pessoas jurídicas, bem como da contribuição social sobre o lucro líquido, e dá outras providências. Recuperado de http://www.planalto.gov.br/ccivil_03/Leis/L9249.htm

Lin, C., Morck, R., Yeung, B., \& Zhao, X. (2016). Anti-corruption reforms and shareholder valuations: Event study evidence from China (No. w22001). National Bureau of Economic Research.

Lintner, J. (1962). Dividends, earnings, leverage, stock prices and the supply of capital to corporations. The review of Economics and Statistics, 243-269.

Loipersberger, F. (2018). The effect of supranational banking supervision on the financial sector: Event study evidence from Europe. Journal of Banking \& Finance, 91, 34-48.

Lonie, A. A., Abeyratna, G., Power, D. M., \& Sinclair, C. D. (1996). The stock market reaction to dividend announcements: A UK study of complex market signals. Journal of Economic Studies, 23(1), 32-52.

Lopes, A. B., Sant'Anna, D. P., \& Costa, F. (2007). A relevância das informações contábeis na Bovespa a partir do arcabouço teórico de Ohlson: avaliação dos modelos de Residual Income Valuation e Abnormal Earnings Growth. Revista de Administração, 42(4), 497-510.

Michaely, R., Thaler, R. H., \& Womack, K. L. (1995). Price reactions to dividend initiations and omissions: Overreaction or drift?. The Journal of Finance, 50(2), 573-608.

Miller, M. H. (1988). The Modigliani-Miller propositions after thirty years. Journal of Economic perspectives, 2(4), 99-120.

Miller, M. H., \& Modigliani, F. (1961). Dividend policy, growth, and the valuation of shares. Journal of Business, 34(4), 411-433.

Miller, M. H., \& Rock, K. (1985). Dividend policy under asymmetric information. The Journal of Finance, 40(4), 1031-1051.

Nel, R., \& Wesson, N. (2019). The timing of dividend declarations based on a forthcoming change in dividend tax regime. South African Journal of Accounting Research, 33(1), 59-75.

Neto, J. A. N., \& Saito, R. (2003). Pagamentos de dividendos e persistência de retornos anormais das ações: evidência do mercado brasileiro. Revista de Administração da Universidade de São Paulo, 38(2).

Ofer, A. R., \& Siegel, D. R. (1987). Corporate financial policy, information, and market expectations: An empirical investigation of dividends. The Journal of Finance, 42(4), 889-911.

Sarlo, A., Nt., Teixeira, A. J. C., Loss, L. \& Lopes, A. B. (2005). O diferencial no impacto dos resultados contábeis nas ações ordinárias e preferenciais no mercado brasileiro. Revista Contabilidade \& Finanças, 16(37), 46-58. 
Sarlo, A., Nt., Lopes, A. B. \& Costa, F. M. (2008). O conteúdo informativo da contabilidade: um estudo sobre o impacto da divulgação das informações contábeis no mercado brasileiro abordando o efeito liquidez. In VI Encontro Brasileiro de Finanças.

Silva, A. D., Souza, T. R. D., \& Klann, R. C. (2016). Tempestividade da informação contábil em empresas familiares brasileiras. Revista de Administração de Empresas, 56(5), 489-502.

Simões, J. J. F. (2017). A Relevância Informacional dos Lucros Contábeis Quanto a Tempestividade da Sua Distribuição aos Acionistas: um Estudo de Evento (Dissertação de mestrado). Universidade Federal do Espírito Santo, Vitória, ES, Brasil.

Simões, J. J. F., Gazoni, G. G., Jr., Sarlo, A., Nt., Porto, P., \& Costa, J., Jr., (2016). Relevância da informação contábil no mercado de capitais: uma análise sobre o teste de impairment no setor de mineração. In III Workshop de Contabilidade e Tributação (Vol. 1, No. 1), Porto, Portugal, 2016, p. 29-30.

Thornton, D. L. (2017). Effectiveness of QE: An assessment of event-study evidence. Journal of Macroeconomics, 52, 56-74. 